\title{
THE COBRA ACCELERATOR PULSED-POWER DRIVER FOR CORNELL/SANDIA ICF RESEARCH
}

\author{
David L. Smith, Pete Ingwersen, Lawrence F. Bennett, and John D. Boyes \\ Sandia National Laboratories, Albuquerque, NM \\ David E. Anderson, John B. Greenly, Ravi N. Sudan, and Dave A. Hammer \\ Cornell University, Ithaca, NY
}

\section{ABSTRACT}

This paper introduces and describes the new Cornell Beam Research Accelerator, COBRA, the result of a three and one-half year collaboration. The flexible 4 to $5-\mathrm{MV}, 100$ to $250-\mathrm{kA}, 46-\mathrm{ns}$ pulse width accelerator is based on a four-cavity Inductive Voltage Adder (IVA) design. In addition to being a mix of new and existing components, COBRA is unique in the sense that each cavity is driven by a single pulse forming line, and the IVA output polarity may be reversed by rotating the cavities $180^{\circ}$ about their vertical axis. Our tests with negative high voltage on the inner MITL stalk indicate that the vacuum power flow has established reasonable azimuthal symmetry within about $2 \mathrm{~ns}$ (or $0.6-\mathrm{m}$ ) after the cavity output gap. Preliminary results with the accelerator, single cavity, and MITL are presented along with the design details and circuit model predictions.

\section{INTRODUCTION}

The new COBRA accelerator shown in Fig. 1 is being built in phases at the Laboratory of Plasma Studies in Cornell University where its applications include extraction diode ion source and ion beam transport research in

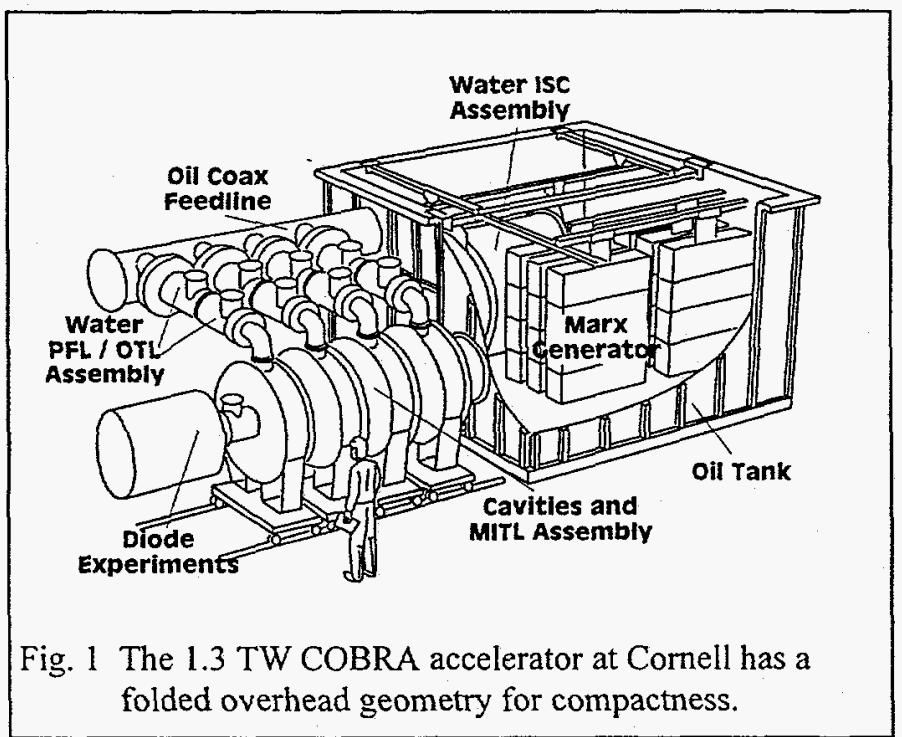
support of the light ion inertial confinement fusion (ICF) program at Sandia National Labs. One of our challenges was to fit the machine within a $6-\mathrm{m}$ wide by $9-\mathrm{m}$ long footprint. In combination with new ferromagnetically-isolated cavities and self magnetically insulated transmission line (MITL) hardware, COBRA includes components from existing Sandia and Cornell facilities. Those are the Marx generator capacitors, hardware, and power supply from the DEMON facility; water pulse forming lines (PFL) and self-breaking $\mathrm{SF}_{6}$ gas switch from the Subsystem Test Facility (STF); a HERMES-III intermediate store capacitor (ISC); and a modified ion diode from Cornell's LION. The present Phase I accelerator consists of a single modified cavity similar to those of the Sandia SABRE accelerator and will be used to perform the first phase lower voltage tests. This cavity contains four of the original inductive isolation cores from the Sandia/PSI HELIA machine. Three liquid resistor dummy loads substitute for the three missing cavities so the pulsed-power driver can perform at its nominal design levels. Four new cavities will be fabricated and delivered in the first half of FY96 to complete the COBRA accelerator in Phase II. The design and limited testing on STF were accomplished at Sandia. The site preparations, tank construction, and diode design and development were done at Cornell, and the machine assembly, initial pulsed-power check-out, and commissioning were conducted by both Sandia and Cornell personnel. Preliminary results with the single cavity and short positive inner cylinder MITL configuration will soon be available. 


\section{DISCLAIMER}

This report was prepared as an account of work sponsored by an agency of the United States Government. Neither the United States Government nor any agency thereof, nor any of their employees, makes any warranty, express or implied, or assumes any legal liability or responsibility for the accuracy, completeness, or usefulness of any information, apparatus, product, or process disclosed, or represents that its use would not infringe privately owned rights. Reference herein to any specific commercial product, process, or service by trade name, trademark, manufacturer, or otherwise does not necessarily constitute or imply its endorsement, recommendation, or favoring by the United States Government or any agency thereof. The views and opinions of authors expressed herein do not necessarily state or reflect those of the United States Government or any agency thereof. 


\section{DISCLAIMER}

Portions of this document may be illegible in electronic image products. Images are produced from the best available original document. 


\section{RESEARCH PLANS}

Ion diode experiments in support of the Sandia ICF program will be the first experimental activity on the Phase I COBRA. The initial one-cavity COBRA is well matched to the extraction geometry, applied-B diode that has been used on the recently decommissioned Cornell accelerator, LION (1.2 MV, $4 \mathrm{Ohm}, 40 \mathrm{~ns}){ }^{1}$ We will field this diode on COBRA to continue ion source studies, particularly addressing the issues of ion species purity and parasitic load with lithium-bearing evaporating metal foil anode plasma source (EMFAPS) active anodes. ${ }^{2}$ Our studies will pursue innovations in foil fabrication and in-diode discharge cleaning techniques begun on LION. ${ }^{3}$ Figure 2 shows a sketch of the LION/COBRA annular ion diode. The insulating magnetic field in the gap is approximately $2 \mathrm{~T}$. Diagnostics will include: magnetically-insulated Faraday cups for beam current density; Rutherford-scattering shadowboxes for ion species-resolved beam divergence; Thompson parabola spectrometer and Rutherford-scattering magnetic spectrometer for ion species and energy composition; collimated bremsstrahlung detectors and in-anode collectors for diode voltage and current; and emission spectroscopy and

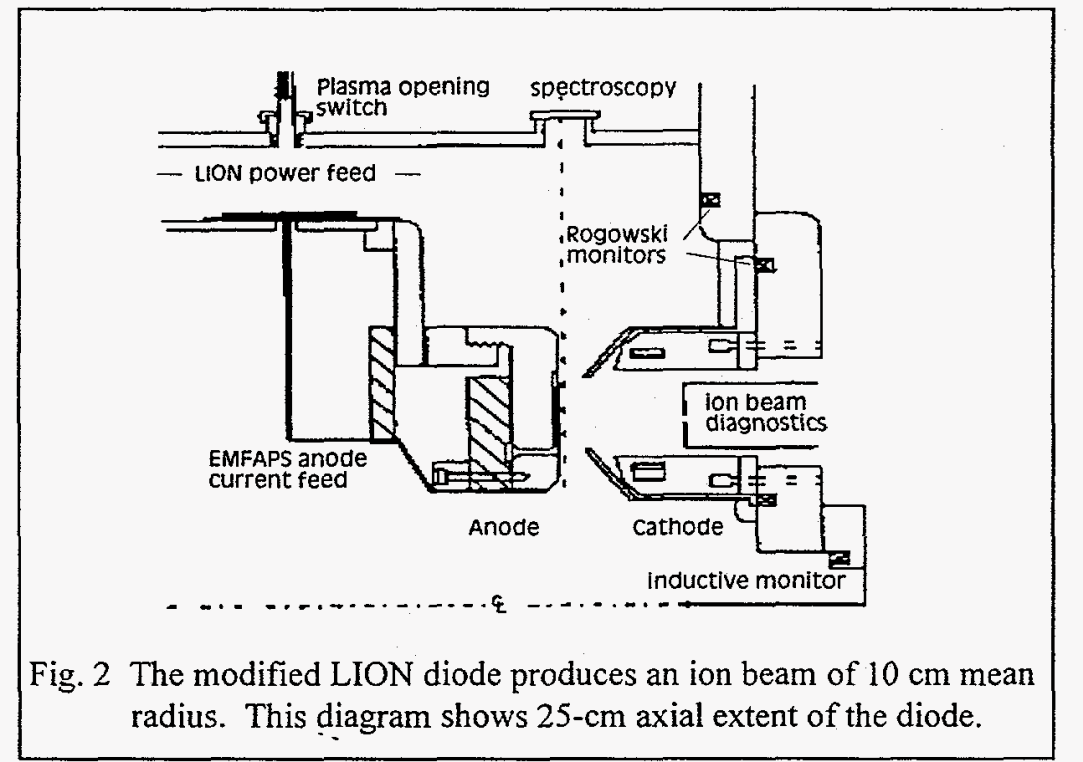
visible light streak photography for ingap light emission.

The substantial data base from the performance of this diode on LION will be compared to results on COBRA to illuminate issues of power coupling to the diode load on the new accelerator. In particular, the diode will first be mounted on COBRA with a very short $(75 \mathrm{~cm}$ from cavity feed gap to diode gap) vacuum MITL. It is expected that with the single-point (azimuthal) power feed to the cavity, power flow in the positive stalk MITL will have significant azimuthal asymmetry. We will diagnose effects of this asymmetry on diode performance. Our aim is to explore the tradeoff between diode performance degradation due to power flow asymmetry for a short MITL and the degradation due to the propagation delay time between the vacuum-wave prepulse and the main power pulse arriving at the diode for the case of a long MITL.

After the full four-cavity COBRA is in place in 1996, the Cornell Phase II experimental program will make a transition from the long-standing emphasis on ion diode physics toward a more integrated development of the diode as part of a beam generation, transport, and focusing system. We will design a system using an extraction diode, a gas-filled transport region, and a solenoidal focusing lens to produce a small analog to a module of a large ICF driver, such as the Laboratory Microfusion Facility (LMF). ${ }^{4}$ The aim will be to diagnose and develop the accelerator, diode, beam transport, and lens as integrated, interacting components of the beam driver system to provide an overview of the issues involved and to investigate the tradeoffs and optimization for LMF.

\section{ACCELERATOR DESCRIPTION}

The requirement for a 4 to $5-\mathrm{MV}$ pulsed power driver led naturally to four 1.0 to $1.25-\mathrm{MV}$ cavities that nearly duplicate the IVA technology presently used in the HERMES-III and "SABRE machines at Sandia. ${ }^{5}$ The. cavity-to-cavity inductive isolation, performed by annular cores made of ribbon-wound 2605CO METGLAS ${ }^{6}$ ferromagnetic material, and the vacuum MITL provide the most compact machine design. As shown in Fig. 3, the inner cylinder of the MITL is tapered at each cavity output feed gap according to the impedance requirements which most efficiently couple to the diode load. Our choice of a single, overhead water line to charge each cavity was influenced by cost and space limitations, but we did confirm that the MITL current flow (for negative polarity operation) was reasonably symmetric within about $2 \mathrm{~ns}(0.6 \mathrm{~m})$ along the vacuum coaxial line from the cavity output gap. See Section VI. These tests were performed at the Sandia STF using the same water lines and cavity 
that are installed for the initial COBRA experimental series. Larger diameter cavities on other IVA machines may need two or more equally spaced feeds to optimize flow symmetry.

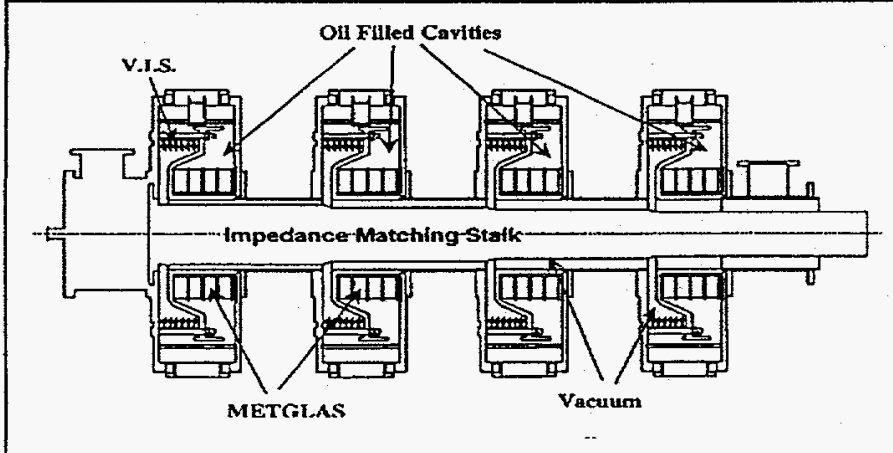

Fig. 3 The COBRA IVA consists of four cavities that deliver power to the coaxial vacuum MITL.
The basic pulsed-power source for the IVA consists of one oil-insulated Marx generator, a water-dielectric ISC or transfer capacitor, a self-breaking multi-stage $\mathrm{SF}_{6}$ gas switch, and water-dielectric coaxial PFLs with self-closing output water switches. The tools we used to iteratively design and model COBRA include the STF experiments, the SCREAMER circuit simulation code ${ }^{7}$ and electrostatic field solvers like $\mathrm{JASON}^{8}$ and ELECTRO ${ }^{9}$ along with dielectric breakdown and flashover criteria like that originated by J.C. Martin. ${ }^{10}$ The following Table $I$ is a summary of the accelerator design parameters, peak values generated by the circuit models, and some of the hardware dimensions.

Negative high voltage is assumed for the inner conductors of the coaxial lines. Note that the subscripts 'in' and 'out' typically refer to the inner and outer coaxial radii, and 'vis' is the oil/vacuum insulator stack. The E/F ratios correspond to the expected electric field stress divided by the calculated breakdown stress. A ratio of $80 \%$ or less is considered a comfortable safety margin.

Table I. Cobra Accelerator Design Summary

\begin{tabular}{|c|c|c|c|c|}
\hline Marx: & $\begin{array}{c}\text { No.Caps }=24 \text { ea. } \\
V_{\text {ch }}=90 \mathrm{kV}\end{array}$ & $\begin{aligned} \mathrm{C} / \mathrm{Cap} & =1350 \mathrm{nF} \\
\mathrm{V}_{\text {rated }} & =100 \mathrm{kV}\end{aligned}$ & $\begin{array}{c}E_{\text {ch }}=131 \mathrm{~kJ} \\
V_{\text {Marx }}=2.2 \mathrm{MV}\end{array}$ & $\begin{array}{l}E_{c h} / E_{\max }=81 \% \\
I_{M a r x}=111 \mathrm{kA}\end{array}$ \\
\hline $\begin{array}{l}\text { C: } \\
\text { (HERMES-III) }\end{array}$ & $\begin{array}{c}\mathrm{R}_{\text {out }}=71.8 \mathrm{~cm} \\
\mathrm{~V}_{\text {isc }}=2.7 \mathrm{MV} \\
\mathrm{E}_{\text {out }}=126 \mathrm{kV} / \mathrm{cm}\end{array}$ & $\begin{array}{c}\mathrm{R}_{\text {in }}=53.3 \mathrm{~cm} \\
\text { Length }=130 \mathrm{~cm} \\
\mathrm{E}_{\text {in }}=170 \mathrm{kV} / \mathrm{cm}\end{array}$ & $\begin{array}{c}\mathrm{C}_{\text {isc }}=19.5 \mathrm{nF} \\
\mathrm{T}_{\text {isc }}=38.6 \mathrm{~ns} \\
\mathrm{E}_{\mathrm{o}} / \mathrm{F}=61 \%\end{array}$ & $\begin{array}{c}Z_{\text {isc }}=1.98 \mathrm{Ohm} \\
T_{\text {eff }}=200 \mathrm{~ns} \\
E_{i} / F=36 \%\end{array}$ \\
\hline $\begin{array}{r}\text { Gas Switch: } \quad \cdots \\
(@ 900 \mathrm{~ns})\end{array}$ & $\begin{array}{c}\text { Length }=50.6 \mathrm{~cm} \\
V_{\text {gas }}=2.7 \mathrm{MV} \\
E_{\text {diss }}=9.4 \mathrm{~kJ}\end{array}$ & $\begin{array}{c}\mathrm{Gap}(\mathrm{x} 18)=16 \mathrm{~cm} \\
I_{\text {gas }}=405 \mathrm{kA} \\
\mathrm{E}_{\text {diss }} / E_{\text {out }}=12 \%\end{array}$ & $\begin{array}{l}\mathrm{OD}=44.5 \mathrm{~cm} \\
\mathrm{~L}_{\mathrm{sw}}=240 \mathrm{nH} \\
\mathrm{Q}_{\mathrm{gas}}>83 \mathrm{mC}\end{array}$ & No.Ch \\
\hline PFLs(4): & $\begin{array}{c}\mathrm{R}_{\text {out }}=17.8 \mathrm{~cm} \\
\mathrm{~V}_{\mathrm{pfl}}=2.3 \mathrm{MV} \\
\mathrm{E}_{\text {out }}=172 \mathrm{kV} / \mathrm{cm}\end{array}$ & $\begin{array}{c}\mathrm{R}_{\mathrm{in}}=8.4 \mathrm{~cm} \\
\text { Length }=76.2 \mathrm{~cm} \\
\mathrm{E}_{\mathrm{in}}=365 \mathrm{kV} / \mathrm{cm}\end{array}$ & $\begin{array}{c}C_{p f l}=4.6 \mathrm{nF} \\
T_{p f 1}=22.8 \mathrm{~ns} \\
E_{0} / F=47 \%\end{array}$ & $\begin{array}{c}\mathrm{Z}_{\mathrm{pfl}}=5.0 \mathrm{Ohm} \\
T_{\text {eff }}=40 \mathrm{~ns} \\
E_{\mathrm{i}} / \mathrm{F}=44 \%\end{array}$ \\
\hline $\begin{array}{r}\mathrm{H}_{2} \mathrm{O} \text { Switches(4): } \\
\text { (@1000 ns) }\end{array}$ & $\begin{array}{l}\mathrm{Gap}=4.2 \mathrm{~cm} \\
\mathrm{E}_{\text {diss }}=2.4 \mathrm{~kJ}\end{array}$ & $\begin{array}{c}\mathrm{L}_{\mathrm{sw}}=66 \mathrm{nH} \\
\mathrm{E}_{\text {diss }} / \mathrm{E}_{\text {out }}=16 \%\end{array}$ & $\begin{array}{l}\mathrm{V}_{\text {wat }}=2.3 \mathrm{MV} \\
\mathrm{Q}_{\text {wat }}>17 \mathrm{mC}\end{array}$ & $\begin{array}{c}I_{\text {wat }}=248 \mathrm{kA} \\
\text { Channels } / \mathrm{Sw}=4\end{array}$ \\
\hline $\begin{array}{l}\text { Cavities(4): } \\
\text { (Matched Load) } \\
(@ 1050 \mathrm{~ns})\end{array}$ & $\begin{aligned} \mathrm{ID} & =38.1 \mathrm{~cm} \\
\mathrm{~V}_{\text {cav }} & =1.31 \mathrm{MV} \\
\mathrm{V}_{\text {load }} & =1.28 \mathrm{MV} \\
\mathrm{P}_{\text {load }} & =328 \mathrm{GW}\end{aligned}$ & $\begin{array}{l}\text { Length }=41.9 \mathrm{~cm} \\
\text { Volt-Sec }=0.077 \\
I_{\text {load }}=256 \mathrm{kA} \\
E_{\text {load }}=12.6 \mathrm{~kJ}\end{array}$ & $\begin{array}{c}\mathrm{OD}=150 \mathrm{~cm} \\
\mathrm{Wt} / \text { Core }=51 \mathrm{~kg} \\
\mathrm{~T}_{\mathrm{r}}(10-90)=23 \mathrm{~ns} \\
4 \mathrm{E}_{\text {load }} / \mathrm{E}_{\mathrm{ch}}=38 \%\end{array}$ & $\begin{array}{c}\mathrm{L}_{\text {cav }}=20 \mathrm{nH} \\
\text { Cores } / \mathrm{Cav}=4 \\
\mathrm{FWHM}=49.2 \mathrm{~ns} \\
\mathrm{E}_{\text {vis }}=87 \mathrm{kV} / \mathrm{cm}\end{array}$ \\
\hline
\end{tabular}

\section{PREDICTED PERFORMANCE}

Our circuit simulation process involved a number of iterations as the COBRA accelerator design evolved and components were modified or better defined. All the feed line lengths, impedance variations, and major component values had to be accurately represented to allow confidence in the model predictions. We used transmission line models in the SCREAMER code, depicted by the boxes in the schematic of Fig. 4, to account for the proper 


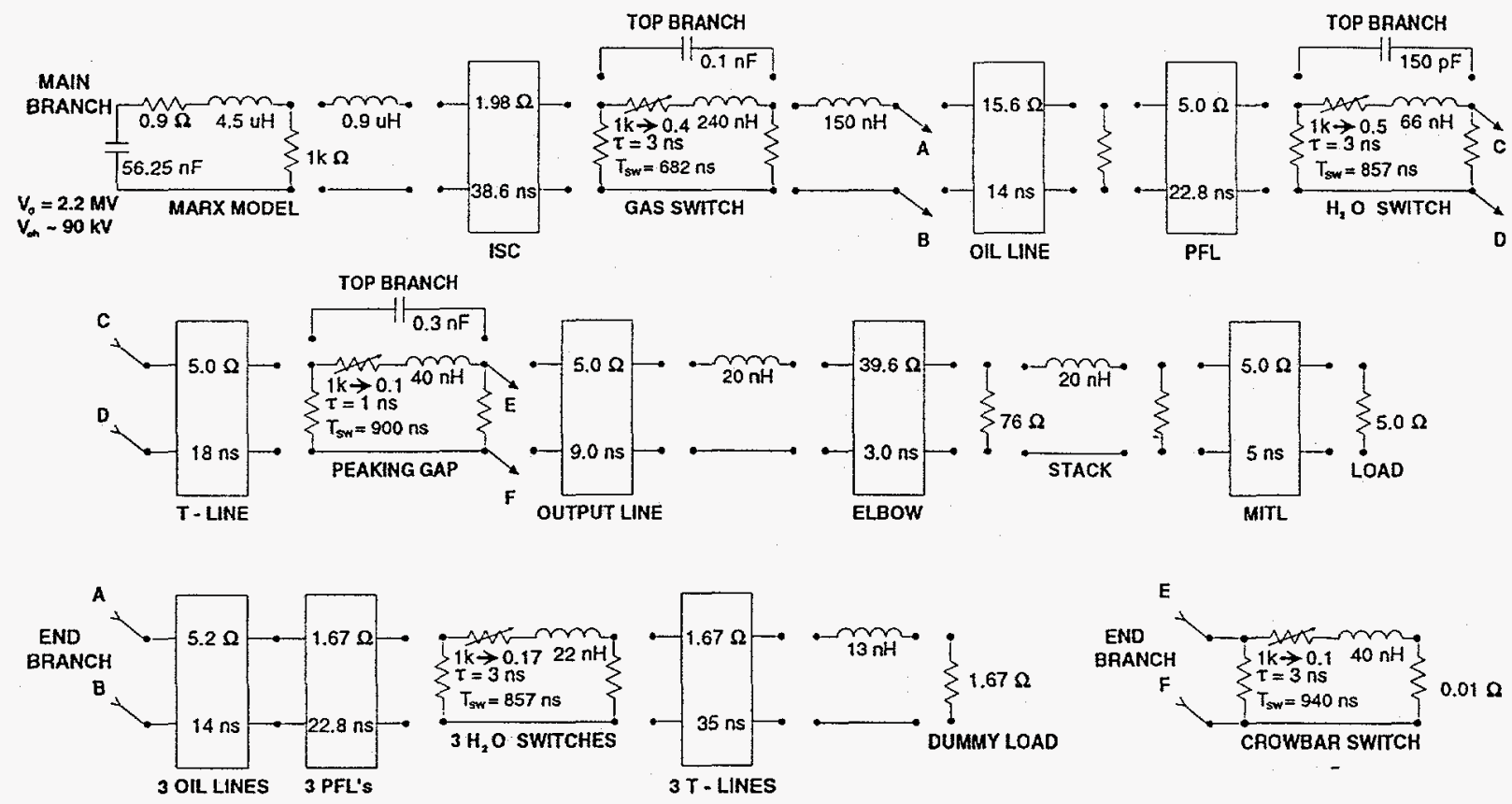

Fig. 4 A typical SCREAMER schematic representing COBRA with three lines/cavities lumped in branch A-B.

physical separations and dimensions of the oil, water, vacuum, and plastic insulated components. These models provide a fixed propagation delay time and either a constant or a linearly tapered line impedance. The switch models are typically represented by the series combination of a time-varying resistor and an appropriate inductor with both elements shunted by a parallel stray capacitance. The switches are closed at about $85-90 \%$ of the peak ring-over voltage by reducing the initial (open state) high resistance exponentially to a final (closed state) low resistance. The exponential time constants were determined from estimates of the resistive and inductive phase contributions to the switching action. " The choice for the final resistance is critical in determining the energy dissipated by the gas and water switches, which in turn affects the forward going pulse shape. All these switch parameters depend directly, or indirectly, on the number of switch channels, $n$, that close and conduct significant current during the main pulse. One conservative procedure to estimate the lower limit to the number of channels is to find the largest integer, $n$, that satisfies the semi-empirical formula, ${ }^{12}$

$$
0.1\left[\tau_{R}(n)+\tau_{L}(n)\right]+0.8 \tau_{T}(n) \geq 2 \sigma_{V} V_{B D}(d V / d t)_{B D}{ }^{-1},
$$

where $\sigma_{\mathrm{V}}$ is the fractional standard deviation of the breakdown voltage, $\mathrm{V}_{\mathrm{BD}}$, and $(\mathrm{dV} / \mathrm{dt})_{\mathrm{BD}}$ is the voltage charging rate at the time of switch closure. The $\tau_{R}$ and $\tau_{\mathrm{L}}$ are the resistive and inductive switching risetimes, and $\tau_{\mathrm{T}}$ is the transit time between channels. For unknown charging wave shapes, experience with similar switches suggests that one may roughly approximate the right hand side of the above expression with twice the onesigma standard deviation of the switch closure time. With careful "tuning" of the switch timing and energy dissipation in our SCREAMER model, the circuit simulation produces waveforms like those in Fig. 5, which shows the voltage transfer

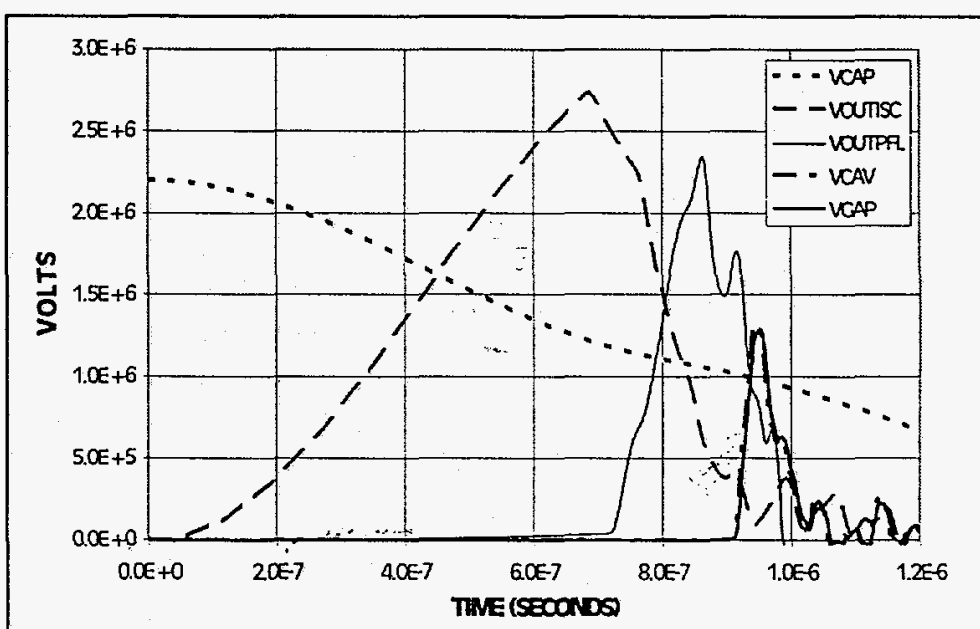

Fig. 5 Voltage transfer through COBRA pulsed-power components. 
through the accelerator and the pulse compression that corresponds to a power gain of approximately 10 . As indicated in Table I, the energy transfer efficiency to a matched load is about $38 \%$.

The cavity input and output voltage waveforms, VCAV and VGAP (=VLOAD), of Fig. 5 are expanded in Fig. 6 to show the results of one circuit simulation that correspond to the parameters listed in Table I. This circuit model did not include a "crowbar" switch in the output water transmission line (OTL) which would close shortly after the primary pulse of interest has passed and shunt late time ringing energy that was not delivered to the load. Also not included was a saturable magnetic core model which would act as a parallel path for the varying loss current during the cavity excitation period. This model could significantly affect the pulse shape depending on the core material properties. Since accurate Child-Langmuir limited ion diode and lossy MITL models are still being developed for SCREAMER, the only load we have modeled is a

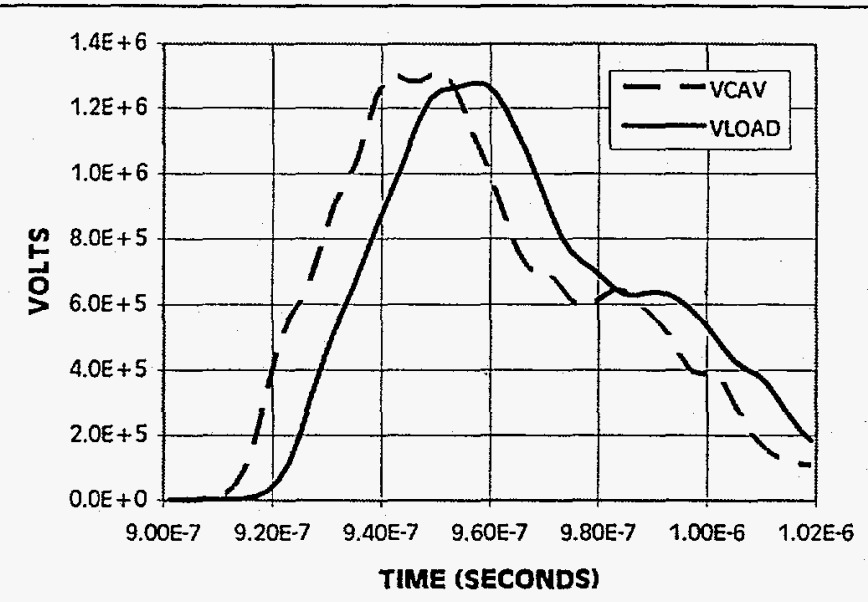

Fig. 6 SCREAMER generated these simulated voltage waveforms at the cavity input and output for a constant matched resistive load. constant matched resistance. The load voltage wave shape will definitely be sensitive to the impedance history of dynamic ion diodes.

\section{PRELIMINARY EXPERIMENTAL RESULTS}

The experiments that we performed on the STF at Sandia Labs included electric field stress tests at and above the maximum expected operating conditions for the water PFLs and OTLs and for the original single cavity to confirm that the pulsed-power hardware was sufficiently robust. We also looked at the power flow symmetry in the coaxial vacuum MITL with shorted, resistive, and electron beam diode loads. The short and resistive load measurements showed uniform current around the coaxial line, but the current had to be limited to a level at which the magnetic insulation probably never turned on. Figure 7 shows peak current data acquired on two $\mathrm{E}$ beam shots with B-dot monitors, located in the MITL 2 ns $(0.6 \mathrm{~m})$ downstream from the cavity output gap and azimuthally separated by $90^{\circ}$. It was only possible to record two inner electrode monitors (dark bars at positions 1 and 3 of Fig. 7) for this shot series due to limited data cable availability. The single PFL/OTL power feed was connected to the outer cavity between the corresponding monitor locations 1 and 2. While the negative inner conductor monitors may not see

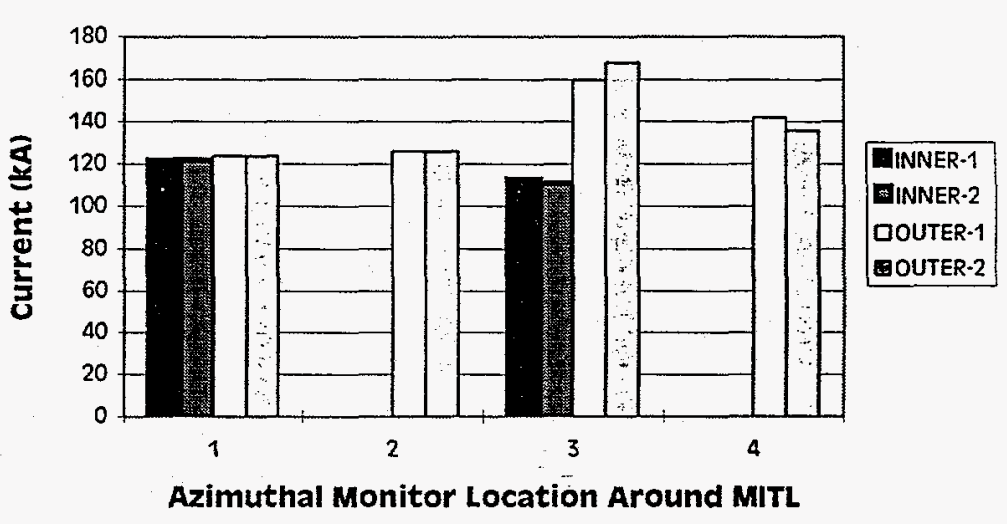

Fig. 7 The inner and outer electrode B-dot monitors produced different peak current results for the same $70-\mathrm{kV}$ charge conditions on STF.

azimuthal current flow asymmetry at that axial location, the B-dots on the positive outer conductor (light bars) may indicate some asymmetry (note higher peak at position 3 ) in either the ground return current or the electron sheath in the vacuum outside the inner conductor. Since the charge accumulation is roughly opposite the feed side, one conclusion is that there are some low amplitude spatial and/or temporal oscillations in the MITL power flow that may or may not be significant to the ion diode performance. These results lead us to the issue concering what MITL extension length offers the best design tradeoffs for the overall system, as referred to in Section III. 
Open switch ring overs of the ISC and PFLs at about half voltage and down line tests delivering current all the way to a shorted diode have been conducted for the preliminary pulsed-power evaluations at Cornell. Instrumentation setup and diagnostics calibration procedures are presently being implemented. The ringing envelope for the ISC ring over indicates that the sum of the Marx and ISC feed inductances is $5.47 \mu \mathrm{H}$, which closely agrees with our SCREAMER model estimates of $4.5 \mu \mathrm{H}$ and $0.9 \mu \mathrm{H}$, respectively. The same data show the equivalent Marx series resistance to be $1.14 \Omega$, instead of our predicted $0.9 \Omega$, meaning that the Marx losses will be somewhat higher. Our near-term plans include slowly raising the operating voltage and adjusting the gas and water switch settings as we continue to compare to the model predictions.

\section{CONCLUSIONS}

With this paper we are announcing a new terawatt class accelerator intended to further the light ion ICF program with research and development of diodes, beam transport, and possibly beam focusing. COBRA is the result of a major cooperative effort between a university and a national laboratory (Cornell and Sandia) and, hopefully, may set a precedent for other similar endeavors. It represents technology currently being applied at Sandia and should be a robust, reliable research tool.

\section{ACKNOWLEDGMENTS}

The authors wish to recognize the long term efforts of Don Cook, Doug Bloomquist, John Maenchen, and Juan Ramirez of Sandia Labs. Without their support this project would never have gone beyond a paper exercise. Special thanks are also due to Dan Jobe and Pat Ryan, Ktech contractors supporting Sandia, and Leo Brissette in Cornell whose enthusiastic support included the preparation, shipping, and assembly of the COBRA hardware at Cornell. Pete Pankuch and Dennis Muirhead were very supportive in the mechanical design, and Chuck Guthrie was instrumental in completing our drafting package. Finally, we appreciate the planning and testing in the early stages of this project by David L. Johnson, John Corley, Gary Dennison, Steve Babcock, and Chip Olson. This work was supported by the U. S. Department of Energy under Contract DE-AC04-94AL85000.

\section{REFERENCES}

1. J.B. Greenly, et. al., "Extraction Ion Diode Studies for Optimized Performance: Divergence, Ion Species, and Parasitic Load," Proc. 10th Intl. Conf. on High Power Particle Beams, San Diego, CA, June, 1994, p. 398 .

2. G.D. Rondeau, Ph.D. Thesis, Cornell University, 1988.

3. C.K. Struckman and B.R. Kusse, J. Appl. Phys. Vol. 74, No. 6, p. 3658, 1993.

4. J.J. Ramirez, et. al., "Design Issues for a Light Ion Beam LMF Driver," Fusion Technol., Vol. 15, p. 350, 1989.

5. J.J. Ramirez, et. al., "The HERMES-III Program," Proc. 6th IEEE Pulsed Power Conf., Arlington, VA, June, 1987, p. 294.

6. METGLAS is Allied Corporation's registered trademark for an amorphous alloy of metals.

7. M.M. Widner and M.L. Kiefer, "SCREAMER - A Pulsed Power Design Tool, User's Guide," Sandia Nat. Labs, Albuquerque, NM, Apr 25, 1985.

8. S.J. Sackett, "JASON - A Code for Solving General Electrostatics Problems, User's Manual," CID-17814, Lawrence Livermore Nat. Labs, Livermore, CA, 1978.

9. "ELECTRO Users and Technical Manual," Version 3.9, Integrated Engineering Software Inc., 46-1313 Border PI., Winnipeg Manitoba, Canada, R3G 2 X7.

10. J.C. Martin, "Nanosecond Pulse Techniques," Internal Report SSWA/JCM/704/49, AWRE, Aldermaston, Berkshire, England, April 1970.

11. J.P. VanDevender and T.H. Martin, IEEE Trans. on Nucl. Sci., Vol. 22, No. 3, p. 979, 1975.

12. J.C. Martin, "Multichannel Gaps," Internal Report SSWA/JCM/703/27, AWRE, Aldermaston, Berkshire, England, 1970. 